Journal of Pediatric Gastroenterology and Nutrition: Publish Ahead Print

DOI: $10.1097 / M P G .0000000000002894$

\title{
Fulminant Wilson's disease in children: Recovery after plasma exchange without transplantation
}

- First and corresponding author: Renee Proost, M.D., University Hospitals Leuven, Department of Pediatrics, Herestraat 493000 Leuven Belgium, email: renee.proost@gmail.com, tel nr: +32 4783385 91, fax: +32 16343842

- David Cassiman, M.D. Ph.D. professor, University Hospitals Leuven, Department of Hepatology

- Elena Levtchenko, M.D. Ph.D. professor, University Hospitals Leuven, Department of Pediatrics

- Eva Morava-Kozicz, M.D. Ph.D. professor, University Hospitals Leuven, Department of Pediatrics

- Jef Neirynck, M.D., University Hospitals Leuven

- Peter Witters, M.D. Ph.D. professor, University Hospitals Leuven, Department of Pediatrics, Herestraat 493000 Leuven Belgium, email: peter.witters@uzleuven.be, tel nr: +3216343827, fax: +3216343842

Conflicts of interest and source of funding

No financial support from any source was received in the realization of this article. None of the contributing authors have any conflicts of interest to declare. 


\section{ABSTRACT}

Objectives - Since 2005 a New Wilson Index (NWI) $\geq 11$ is used as a predictor of death without transplantation in fulminant Wilson's disease (WD). Plasma exchange is advocated as a new treatment modality.

Methods - We present a patient with fulminant WD treated with plasma exchange. All published cases applying plasma exchange for fulminant WD were reviewed systematically. Results - A 14-year-old girl presented with hemolysis and fulminant liver failure. She had no encephalopathy; NWI was 14 . As a bridge to transplantation plasma exchange was started immediately. Complete remission was achieved with plasma exchange and later chelation therapy with D-penicillamine. She is now at 3-year transplant free survival. Literature review identified 37 patients presenting with fulminant WD and NWI $\geq 11$ who were treated with plasma exchange. Seventeen of these patients (i.e. 46\%) recovered without transplantation. Conclusions - Multiple case reports and case series demonstrate transplant free survival after plasma exchange and subsequent chelation therapy, despite a NWI $\geq 11$. Plasma exchange affects the clinical course and is a therapeutic option in children and young adults presenting with fulminant WD. 


\section{What is known}

- Liver transplantation is curative in case of fulminant Wilson's disease (WD)

- New Wilson Index (NWI) $\geq 11$ has been used as indicator for transplantation in these cases

- Plasma exchange has been reported to stabilize patients with fulminant WD

\section{What is new:}

- Review of literature shows survival after plasma exchange without transplantation in numerous children and young adults with NWI $\geq 11$

- Plasma exchange should be considered as a treatment for fulminant WD at least as a bridge to transplantation

\section{Introduction}

Wilson's disease (WD) is an autosomal recessive genetic disorder of copper metabolism with an estimated prevalence between 1:30000 and 1:50000 (1). The $A T P 7 B$ gene which encodes a transmembrane copper transporting P-type ATPase is mutated in patients with WD. Excretion of copper from hepatocytes into bile is compromised, which leads to accumulation of copper in hepatocytes and subsequent injury to the liver. Absence of the ATP7B also makes incorporation of copper into ceruloplasmin defective. As a result unbound (free) copper is released into the bloodstream and will over time deposit in other organs $(2,3)$.

Diagnosis and treatment recommendations in children are summarized in a recent society paper of European Society for Paediatric Gastroenterology Hepatology and Nutrition (ESPGHAN)(3). The presentation is mostly subclinical and frequently limited to elevated serum transaminases. Nevertheless, as copper accumulates over time during childhood, fulminant presentation with acute liver failure (ALF) and hemolytic anemia is possible (4). In fact, this presentation with acute liver failure is reported in $7 \%$ to $50 \%$ of children presenting 
with WD according to different cohorts $(5,6)$. Such a fulminant presentation can be provoked by infection or medication. Moreover, presence of infection, non-alcoholic fatty liver disease (NAFLD) or auto-immune hepatitis (AIH) do not exclude diagnosis of WD and autoantibodies may be found in WD $(2,3)$. Kayser-Fleischer rings are pathognomonic for WD but are often absent in children, serum copper and ceruloplasmin are not reliable in the context of acute liver failure and even elevated liver copper on biopsy and 24-hour urinary copper excretion can be uncertain in diagnosing WD. A combination of diagnostic tools was used to create an applicable flowchart by Roberts et al. in 2008 (2). The Ferenci score, first published in 2001, was endorsed by the ESPGHAN committee because of good sensitivity and specificity in available studies. However, when a patient presents with fulminant liver failure these examinations and diagnostic tools will take too long or will be impossible due to the critical state of the patient. Acute diagnosis can be suspected using biochemical parameters such as AST/ALT ratio and Alkaline Phosphatase (ALP)/bilirubin ratio $(7,8)$. Treatment with chelators (D-penicillamine, trientine) and/or zinc salts should always be started at diagnosis. In patients presenting with fulminant WD this will rarely suffice. Liver transplantation seems the only lifesaving therapy for these patients. Back in 1986 prognostic criteria where described by Nazer et al. as an index for death without liver transplantation (9). In 2005 Dhawan et al. revised this score by conducting a retrospective analysis of children with WD and the score was tested in 14 children (6). The New Wilson index (NWI) is based upon the lab values of bilirubin, INR (International Normalized Ratio), AST, white blood cell count and albumin. A score of 11 or more predicted death without transplantation with a $93 \%$ sensitivity and $98 \%$ specificity. 1 of the 14 children (i.e. $7 \%$ ) with a score of 11 however survived without transplantation. Dhawan et al. already stated that the index, although more sensitive and specific, still needs to be validated in a larger cohort of patients. While the score has been widely used since, it hasn't been validated. There is the risk of this score becoming 
a self-fulfilling prophecy as liver transplantation is available as a therapeutic option. Over the last 30 years sporadic publications mention plasma exchange (PE) as a possible bridge to transplantation in patients presenting with fulminant WD.

In fulminant Wilson's disease liver cell necrosis causes high levels of free circulating copper, which damages the red blood cell membrane and causes hemolytic anemia. Furthermore, all classic symptoms of liver failure, and often renal failure, are present. There are multiple reasons why PE might be lifesaving in such circumstances. Under normal circumstances serum copper is mostly (90-95\%) ceruloplasmin bound. In fulminant Wilson's disease however copper is mostly unbound, with free copper mostly binding to albumin. Because of this, regular hemodialysis shows little effect in fulminant WD. In contrast, PE removes all types of copper, bile acids and bilirubin from the bloodstream and can stabilize the patient. Additionally, PE with fresh frozen plasma will also replace coagulation factors and albumin. Fresh frozen plasma is readily available in most hospitals. Adverse events such as hypocalcemia are easily treated. $(3,10,11)$.

Here we present a patient with WD (fulminant liver failure and hemolysis) and an NWI of 14 that underwent plasma exchange resulting in transplant-free survival. Analysis of published cases suggests that plasma exchange could alter the natural history significantly.

\section{Methods}

Case report

A 14-year-old girl presented with symptoms of liver failure and deep hemolytic anemia. When she was 7 years old, elevated transaminases were found on a routine blood test. At the age of 10 she was further evaluated because of abdominal pain and dizziness with persistent abnormal liver tests. Ultrasound showed steatosis. Liver biopsy showed steatohepatitis with fibrosis Metavir F2 and copper levels of $120 \mu \mathrm{g} / \mathrm{g}$ dry weight (normal $<40-50 \mu \mathrm{g} / \mathrm{g}$ dry 
weight (1)). No further diagnostics to exclude WD were performed. Supplementation of ursodeoxycholic acid $300 \mathrm{mg}$ twice daily, vitamin E $100 \mathrm{mg}$ and zinc sulphate $100 \mathrm{mg}$ was started. Because of ongoing complaints, an MRI was performed at the age of 13 which showed hepatomegaly and liver steatosis. She was transferred to our hospital at the age of 14 with complaints of abdominal pain and nausea, fatigue, shortness of breath and weight gain. There were pale stools and dark urine. Tremor, dizziness and transpiration existed for some days before admission. There was no acute infectious episode reported. A $3 \mathrm{~kg}$ weight gain over a few days was objectified. She was cardiocirculatory stable, temperature was $37.5^{\circ} \mathrm{C}$, blood pressure was $108 / 63 \mathrm{mmHg}$ with a pulse of $100 / \mathrm{min}$. She was fully oriented. There was obvious jaundice. She had a distended abdomen with hepatomegaly. Malleolar edema was found. Her labs showed abnormal liver function tests with high AST/ALT ratio of 5.6 and liver function was severely impaired with INR of 2.6 (Table 1). A deep hemolytic anemia was present with a hemoglobin of 5.4 g/dL (normal 12.0-16.0 g/dL) (Table 1). Direct Coombs test was negative. Abdominal ultrasound confirmed obvious ascites in the lower abdomen, chest X-ray showed pleural effusion. Our patient had decompensated cirrhosis MELD 24, Child Pugh C 12. Her copper level was elevated to a value of $168 \mu \mathrm{g} / \mathrm{dL}$ (80-140 $\mu \mathrm{g} / \mathrm{dL})$. Ceruloplasmin was low but still in the normal range: $0.23 \mathrm{~g} / \mathrm{L}(0.22-0.58 \mathrm{~g} / \mathrm{L})$. She had a high urinary copper excretion of $14156 \mu \mathrm{g} / \mathrm{g}$ creatinine on 24 hours urine collection $(<$ $50 \mu \mathrm{g} / \mathrm{g}$ creatinine). There were no Kayser-Fleischer rings. The genetic diagnosis of Wilson's disease was later confirmed when she was found to be homozygous for a c.3207C $>\mathrm{A}$ mutation (p.His1069Gln) on exon 14 of the $A T P 7 B$ gene.

\section{Review of literature}

We performed a systematic search of literature using following MESH terms on PubMed: ((Wilson's disease) OR (fulminant Wilson's) OR ("Wilson disease")) AND ((plasmapheresis) OR (plasma exchange) OR (total plasma exchange) OR (score)). Papers published between 
1989 and 2019 were included. Exclusion criteria were non-English papers and papers not discussing PE as a treatment. See Figure, Supplemental Digital Content 1, which demonstrates the review process. Ethical approval for this study was granted by the Ethics Committee Research of the University Hospitals Leuven (nr. MP014998).

\section{Results}

Case

The patient was immediately admitted and urgent packed cell transfusions, IV fluids, diuretics, vitamin K and antibiotics were administered. An NWI of 14 was calculated at admission, therefore she was listed for liver transplantation. Within 24 hours of presentation PE was started as rescue therapy. Initially 5 sessions were performed, spread over 5 days. During every session 3 liters of plasma were exchanged for fresh frozen plasma over 2 hours. Hypocalcemia was compensated by administrating calcium gluconate. The patient remained hemodynamically stable during the procedures. After these sessions hemolysis and liver function were spectacularly improved. 3 days after the last session INR started to rise again (reaching 3.9), hemolysis reappeared and eventually 5 extra sessions were performed. After these, we saw persisting stabilization of liver function. She was started on D-penicillamine $250 \mathrm{mg}$ per day orally, which was augmented to $500 \mathrm{mg}$ twice a day over the following 4 weeks. She was discharged a little over a month after admission in good clinical condition (except for fatigue) and slowly improving hepatic function. She then had a MELD score of 20 and a Child-Pugh was B7. Chelation therapy was continued. 2 months after initial admission she was relisted for liver transplant because of progressive liver failure, but subsequently deactivated because of improvement 6 months after the initial presentation. Regular follow up showed further normalization of liver function. The patient now has normal liver function 
tests and no clinical symptoms more than 3 years after the episode of acute liver failure. (Figure 1)

\section{Review of literature}

Our search resulted in 218 papers. After reading titles and abstracts 45 papers were included as relevant. After excluding non-English papers, papers not discussing PE as a treatment, or papers reviewing patients already included, 29 papers were withheld in which pediatric and young adult patients were treated with PE for acute liver failure in WD (1). A total of 63 patients were described. Patients were aged 5 to 30 years old. Twenty-five patients $(40 \%)$ survived with PE alone, 28 patients (44\%) received a liver transplant and 10 patients (16\%) died. Thirty-seven patients had an NWI $\geq 11$. In 17 patients $(47 \%)$ with known NWI $\geq 11$ treatment with PE resulted in complete recovery from fulminant WD without transplant. In 12 patients $(33 \%)$ with known NWI $\geq 11$ treatment with PE served as a bridge to transplant (table 2). At least 3 patients had clinical stabilization with PE before receiving transplant. Out of 10 known patients who died, 8 had NWI $\geq 11$, in 2 patients NWI could not be calculated. Twenty-seven patients were reported having at least encephalopathy grade I or mental changes. Nine patients had renal failure requiring continuous renal replacement therapy (CRRT). From the available data a sensitivity of $86 \%$ and a specificity of $15 \%$ was calculated for the NWI. Chi square test demonstrates that patients with NWI $\geq 11$ who received PE in fulminant WD had a similar likelihood to be transplanted or to recover without transplantation $(\mathrm{p}=0.95)$.

\section{Discussion}

Prognostic indices predicting mortality without transplantation are in general problematic in circumstances where liver transplant is available. All patients meeting the criterium will be more likely to be transplanted. Hence, it is impossible to develop an adequate prediction rule 
when liver transplantation in an available therapeutic option. Nevertheless, we suggest that the use of PE can alter the outcome in fulminant WD. The NWI cut-off predicting poor outcome without transplantation was initially proposed at 11 , however as noted in the original paper, larger validation studies are needed(6).

In 2018 the ESPGHAN Hepatology Committee published recommendations for diagnosis, treatment and follow-up of children with WD(3). Children with ALF or decompensated cirrhosis should be treated with chelating agents and/or zinc salts, and if needed liver transplantation is to be considered. The NWI is to be monitored for prognostic assessment and decision making for liver transplantation. Extracorporeal liver support systems such as $\mathrm{PE}$ are indeed mentioned as a bridge to transplantation. Our review suggests treatment with such bridging therapies can be lifesaving if no donor liver is readily available. Furthermore, liver transplantation, although curative, is not without risk. A large European study including 95\% of liver transplantations performed in children with WD between 1968 and 2013 shows $84 \%$ survival at 5 years, with better results after the year 2000 and increasing to $93 \%$ survival at 1 year after 2010. Patients aged younger than 10 were at greater risk of dying (12). Morbidity and quality of life following transplantation should also be taken into consideration.

Our case is one of multiple cases where liver transplantation could be avoided despite having an NWI $\geq 11$ at presentation. A diagnosis of WD was quickly confirmed and supportive therapy was started as soon as possible. Within 24 hours after admission PE was started in parallel with listing for transplantation. Although it took up to 6 months to completely stabilize the patient's liver function, no transplantation was necessary up to 3 years after presentation despite the unfavorable prognosis at admission. In most cases reported, liver transplantation was performed shortly after diagnosis. Kido et al. presented a patient in whom it took 9 months for liver tests to normalize after plasma exchange (13). It is possible that 
more sessions of PE and longer waiting time after stabilization would have allowed recovery and prevented the need for transplantation in other cases as well. It is however a difficult consideration to wait when a donor liver is available.

After reviewing existing literature, we found that some patients with NWI $<11$ were transplanted and more importantly 17 patients with NWI $\geq 11$ survived after PE treatment and chelation therapy, as demonstrated by the low specificity of $15 \%$ of the score (Figure 2). Multiple authors pointed to hepatic encephalopathy and kidney failure as predicting factors for mortality without transplantation. We don't have information about encephalopathy for all patients, however in most recovered patients there was no more than grade 1. Based upon available data it is not possible to say that hepatic encephalopathy alone is a predictor of death without transplant. Moreover HE in WD patients might be difficult to distinguish from central nervous system involvement in WD. Presence of kidney failure with need for CRRT could determine outcome in fulminant WD. Our patient did not have kidney failure. In a recent study by Alam et al., 66 children were followed after diagnosis of acute liver failure or decompensated chronic liver failure in WD. Of 12 patients who had a NWI $\geq 11$ and received chelation therapy and PE, 4 survived up to 90 days without transplantation(14). They studied the AARC-ACLF score on this cohort to predict mortality without transplantation in comparison to the NWI. This score includes bilirubin, INR, lactate, creatinine and hepatic encephalopathy grade. In their cohort, the AARC-ACLF score predicted mortality with higher sensitivity and specificity in comparison with the NWI. Our patient's AARC-ACLF score was 8 grade II which predicts $70 \%$ survival at 13 weeks based on their cohort. Other medical therapies such as molecular adsorbent recirculating system (MARS) and single pass albumin dialysis (SPAD) have been reported in a few case reports and series as treatment modality for fulminant WD $(11,15-19)$. These methods could also be effective in removing copper from the blood stream, however plasma exchange is more readily available 
and might support the synthetic function of the liver. Further research is warranted to determine the role of these treatments in fulminant WD.

We acknowledge limitations to this review. Firstly, most data are collected from case reports and small series. However, performing randomized controlled trials might be difficult due to low prevalence of ALF WD patients and the ethical considerations already mentioned above. Secondly, several authors reported different data and outcomes. For example, NWI could not be calculated for all patients included. The strength of this review is that all published data on PE as treatment in WD is included. NWI indices where calculated where possible to expose the difficulties with interpreting prognostic indices in these cases. We looked for additional prognostic factors like encephalopathy and kidney failure, however further research will be necessary.

In conclusion, plasma exchange should be considered as a treatment for fulminant Wilson's disease in children and young adults despite high NWI, at least as a bridge to transplantation.

\section{References}

1. Sandahl TD, Laursen TL, Munk DE, et al. The Prevalence of Wilson's Disease: An Update. Hepatology. 2020;71(2):722-32.

2. Roberts EA, Schilsky ML, (AASLD) AAfSoLD. Diagnosis and treatment of Wilson disease: an update. Hepatology. 2008;47:2089-111.

3. Socha P, Janczyk W, Dhawan A, et al. Wilson's Disease in Children: A Position Paper by the Hepatology Committee of the European Society for Paediatric Gastroenterology, Hepatology and Nutrition. J Pediatr Gastroenterol Nutr. 2018;66:334-44.

4. Rukunuzzaman M. Wilson's Disease in Bangladeshi Children: Analysis of 100 Cases. Pediatr Gastroenterol Hepatol Nutr. 2015;18:121-7. 
5. Walshe JM. The acute haemolytic syndrome in Wilson's disease--a review of 22 patients. QJM. 2013;106:1003-8.

6. Dhawan A, Taylor RM, Cheeseman P, et al. Wilson's disease in children: 37-year experience and revised King's score for liver transplantation. Liver Transpl 2005;11:441-8.

7. Eisenbach C, Sieg O, Stremmel W, et al Diagnostic criteria for acute liver failure due to Wilson disease. World J Gastroenterol. 2007;13:1711-4.

8. Güngör Ş, Selimoğlu MA, Bağ HGG, et al. Is it possible to diagnose fulminant Wilson's disease with simple laboratory tests? Liver Int. 2020;40:155-62.

9. Nazer H, Ede RJ, Mowat AP, et al. Wilson's disease: clinical presentation and use of prognostic index. Gut. 1986;27:1377-81.

10. Zhang Y, Li L, Zhang X, et al. Plasmapheresis Combined with Continuous Plasma Filtration Adsorption Rescues Severe Acute Liver Failure in Wilson's Disease before Liver Transplantation. Blood Purif. 2019;47(1-3):120-5.

11. Reynolds HV, Talekar CR, Bellapart J, et al. Copper removal strategies for Wilson's disease crisis in the ICU. Anaesth Intensive Care. 2014;42:253-7.

12. Pfister ED, Karch A, Adam R, et al. Predictive Factors for Survival in Children Receiving Liver Transplants for Wilson's Disease: A Cohort Study Using European Liver Transplant Registry Data. Liver Transpl. 2018;24:1186-98.

13. Kido J, Matsumoto S, Momosaki K, et al. Plasma exchange and chelator therapy rescues acute liver failure in Wilson disease without liver transplantation. Hepatol Res. $2017 ; 47: 359-63$.

14. Alam S, Lal BB, Sood V, et al. AARC-ACLF score: best predictor of outcome in children and adolescents with decompensated Wilson disease. Hepatol Int. 2019;13(3):330-8. 15. Markiewicz-Kijewska M, Szymczak M, Ismail H, et al. Liver transplantation for fulminant Wilson's disease in children. Ann Transplant. 2008;13:28-31. 
16. Manz T, Ochs A, Bisse E, et al. Liver support--a task for nephrologists?

Extracorporeal treatment of a patient with fulminant Wilson crisis. Blood Purif. 2003;21:232-

6.

17. Kreymann B, Seige M, Schweigart U, et al. Albumin dialysis: effective removal of copper in a patient with fulminant Wilson disease and successful bridging to liver transplantation: a new possibility for the elimination of protein-bound toxins. J Hepatol. $1999 ; 31: 1080-5$.

18. Rustom N, Bost M, Cour-Andlauer F, et al. Effect of molecular adsorbents recirculating system treatment in children with acute liver failure caused by Wilson disease. $\mathrm{J}$ Pediatr Gastroenterol Nutr. 2014;58(2):160-4.

19. Jain V, Dhawan A. Quest for Life on MARS: mission incomplete. J Pediatr Gastroenterol Nutr. 2014;58(2):140-1. 


\section{Legends}

Figure 1. This graph illustrates the evolution of our patient's laboratory results after PE. We see complete normalization of hemoglobin and liver function tests after 6 months.

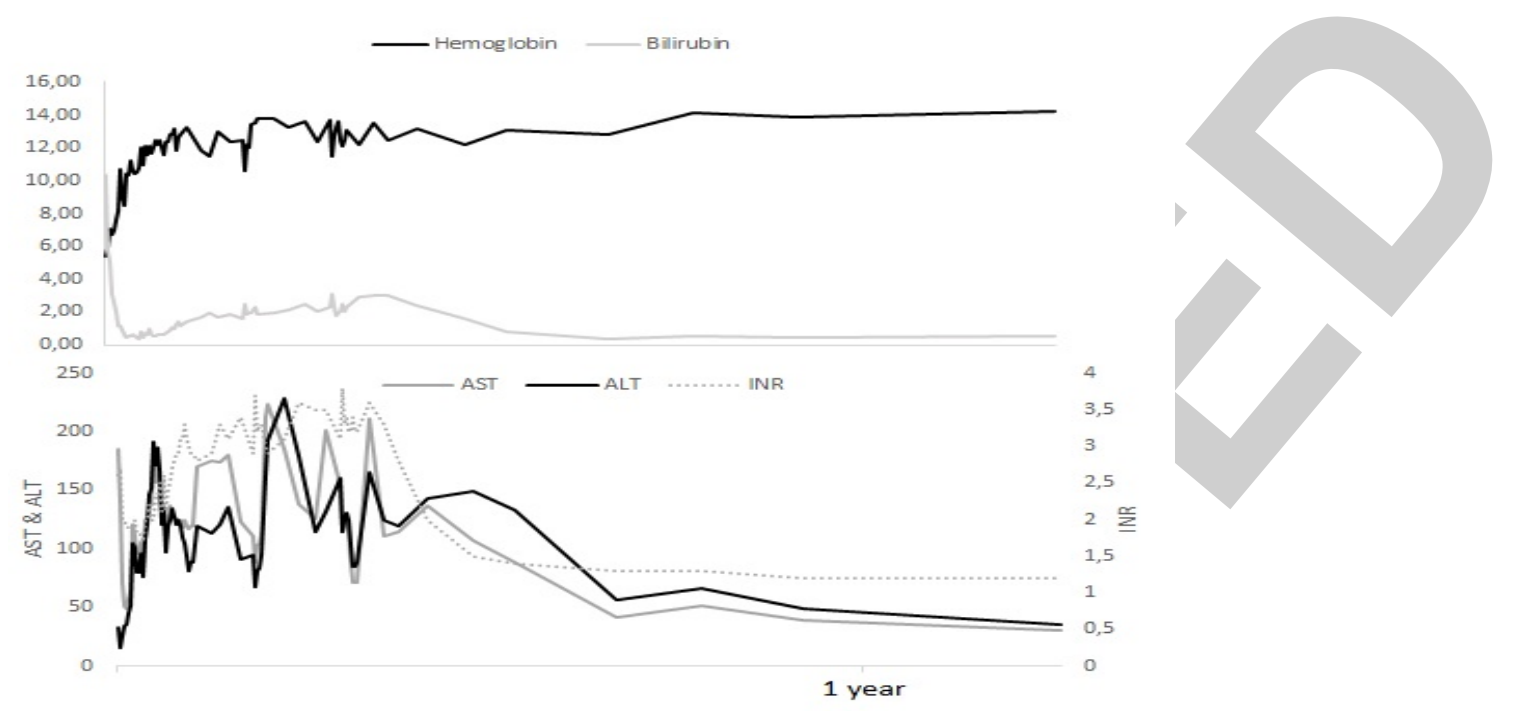




\begin{tabular}{|c|c|c|c|c|c|c|c|c|}
\hline Author & Year & Patients (n) & Age (years) & NWI & $\begin{array}{l}\text { Outcome } \\
\text { (recovery/transplant/death) }\end{array}$ & Sessions PE & $\begin{array}{l}\text { Hepatic } \\
\text { encephalopathy }\end{array}$ & CRRT \\
\hline $\begin{array}{l}\text { Enomoto et } \\
\text { al.(15) }\end{array}$ & 1989 & 1 & 16 & NA & Death & $>1$ & Yes & \\
\hline $\begin{array}{l}\text { Sarles et } \\
\text { al.(16) }\end{array}$ & 1992 & 1 & 15 & NA & Recovery & 4 over 6 days & Yes & \\
\hline Lee et al.(17) & 1998 & 1 & 27 & $\geq 11$ & Death & 2 & No & \\
\hline $\begin{array}{l}\text { Kiss et } \\
\text { al.(18) }\end{array}$ & 1998 & 2 & 19,16 & NA & All transplant & 4 over 4 days & Yes/No & \\
\hline $\begin{array}{l}\text { Matsumura } \\
\text { et al.(19) }\end{array}$ & 1999 & 1 & 17 & NA & Recovery & 3 over 3 days & NA & \\
\hline $\begin{array}{l}\text { Nagata et } \\
\text { al.(20) }\end{array}$ & 2003 & 1 & 15 & $\geq 11$ & Transplant & 4 over 3 days & Yes & Yes \\
\hline $\begin{array}{l}\text { Rodriguez et } \\
\text { al.(21) }\end{array}$ & 2003 & 1 & 19 & NA & Recovery & 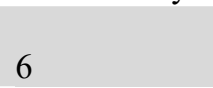 & No & \\
\hline $\begin{array}{l}\text { Valbonesi et } \\
\text { al.(22) }\end{array}$ & 2003 & 1 & 27 & NA & Transplant & 20 & Yes & \\
\hline $\begin{array}{l}\text { Kitazawa et } \\
\text { al.(23) }\end{array}$ & 2004 & 1 & 14 & NA & Transplant & 6 over 6 days & Yes & \\
\hline $\begin{array}{l}\text { Harmanci et } \\
\text { al.(24) }\end{array}$ & 2006 & 1 & 17 & 16 & Recovery & 7 over 7 days & Yes & \\
\hline $\begin{array}{l}\text { Jhang et } \\
\text { al.(25) }\end{array}$ & 2007 & 1 & 21 & $\geq 15$ & Transplant & 5 over 6 days & Yes & Yes \\
\hline $\begin{array}{l}\text { Asfaha et } \\
\text { al.(26) }\end{array}$ & 2007 & 1 & 18 & 9 & Recovery & 7 over 7 days & No & \\
\hline $\begin{array}{l}\text { Hursitoglu et } \\
\text { al.(27) }\end{array}$ & 2009 & 1 & 17 & NA & Transplant & $x^{2}+5$ & No & Yes \\
\hline $\begin{array}{l}\text { Fischer et } \\
\text { al.(28) }\end{array}$ & 2011 & 1 & 17 & 13 & Recovery & NA & No & \\
\hline $\begin{array}{l}\text { Oosthuizen } \\
\text { et al.(29) }\end{array}$ & 2011 & 1 & 21 & NA & Recovery & 4 & No & \\
\hline $\begin{array}{l}\text { Akyildiz et } \\
\text { al.(30) }\end{array}$ & 2011 & 1 & 9 & 16 & Recovery & 5 & Yes & \\
\hline $\begin{array}{l}\text { Morgan et } \\
\text { al.(31) }\end{array}$ & 2012 & 1 & 6 & 14 & Transplant & 5 & No & \\
\hline $\begin{array}{l}\text { Narumi et } \\
\text { al.(32) }\end{array}$ & 2012 & 3 & $14,12,10$ & 14,11 , & All transplant & $5,3,5$ & Yes & Yes \\
\hline
\end{tabular}

Copyright $\odot$ ESPGHAN and NASPGHAN. All rights reserved. 


\begin{tabular}{|c|c|c|c|c|c|c|c|c|}
\hline $\begin{array}{l}\text { Verma et } \\
\text { al.(33) }\end{array}$ & 2013 & 1 & 5 & NA & Death & 7 & Yes & $\begin{array}{l}\text { Renal } \\
\text { failure }\end{array}$ \\
\hline $\begin{array}{l}\text { Ohya et } \\
\text { al.(34) }\end{array}$ & 2013 & 3 & $13,6,15$ & $15,10,12$ & 2 transplant, 1 recovery (NWI 15$)$ & NA & Yes & \\
\hline $\begin{array}{l}\text { Motobayashi } \\
\text { et al.(35) }\end{array}$ & 2014 & 1 & 10 & 16 & Recovery & 10 & Yes & Yes \\
\hline $\begin{array}{l}\text { Hilal et } \\
\text { al.(36) }\end{array}$ & 2014 & 1 & 19 & 16 & Transplant & 3 over 2 days & Yes & Yes \\
\hline $\begin{array}{l}\text { Pham et } \\
\text { al.(37) }\end{array}$ & 2016 & 10 & 6 to 30 & NA & 1 recovery, 9 transplant & $\begin{array}{l}1 \text { to } 9 \text { over } 1 \text { to } \\
13 \text { days }\end{array}$ & $5 / 10$ mental changes & \\
\hline $\begin{array}{l}\text { Tian et } \\
\text { al.(38) }\end{array}$ & 2016 & 7 & $\begin{array}{l}7,8,13,16,17 \\
22,15\end{array}$ & $\begin{array}{l}13,15,12,11,14 \\
10,15\end{array}$ & 6 recovery, 1 death & 10 engo 5 & Survivors grade 0 -II & \\
\hline $\begin{array}{l}\text { Kido et } \\
\text { al.(13) }\end{array}$ & 2016 & 4 & $6,15,13,10$ & $11,12,15,8$ & $\begin{array}{l}2 \text { transplant (NWI 11, 12), } 2 \text { recovery } \\
(\mathrm{NWI} 15,8)\end{array}$ & NA & Survivors grade I & \\
\hline $\begin{array}{l}\text { Damsgaard } \\
\text { et al.(39) }\end{array}$ & 2018 & 1 & 27 & 16 & Recovery & 12 & Yes & Yes \\
\hline Liu et al.(40) & 2019 & 1 & 13 & 15 & Recovery & 14 over 14 days & NA & \\
\hline $\begin{array}{l}\text { Zhang et } \\
\text { al.(10) }\end{array}$ & 2019 & 1 & 7 & 16 & Transplant & 9 & Yes & \\
\hline $\begin{array}{l}\text { Alam et } \\
\text { al.(14) }\end{array}$ & 2019 & 12 & $<18$ & $\geq 11$ & 4 recovery, 6 death, 2 transplant & $>3$ & NA & \\
\hline
\end{tabular}

Copyright @ ESPGHAN and NASPGHAN. All rights reserved. 